\title{
LECTURA Y DIFUSIÓN DE LOS LIBROS DE SÉNECA (A PROPÓSITO DE UN TESTIMONIO DESCONOCIDO)
}

\author{
María MORRás \\ Universidad Pompeu Fabra \\ Maria Merce lópez Casas \\ Universidad de Santiago de Compostela
}

\section{INTRODUCCIÓN}

A juzgar por el número de manuscritos conservados, a los que hay que añadir un incunable (Sevilla, Meinhard Ungut, 1491; teimpreso cuatro veces: Toledo, 1510; Alcalá de Henares, 1530; Amberes, 1548 y 1551), pocas obras gozaron de tanto éxito en el Cuatrocientos castellano como las de Séneca en la versión llevada a cabo por Alfonso de Cartagena. A la cuarentena de códices conocidos hasta ahora hay que sumar un nuevo testimonio que había permanecido hasta el momento sin identificar en los anaqueles del convento de San Francisco de Santiago de Compostela. La dificultad de acceso al catálogo, cuya existencia está por confirmar, el carácter semi-privado de la biblioteca del convento y la aparente ausencia de libros medievales entre sus fondos explican que el volumen haya escapado a la labor de localización y catalogación de otros estudiosos, singularmente a los empeños bibliográficos de $\mathrm{Ch}$. Faulhaber y sus colaboradores. Sin embargo, la extraordinaria popularidad de estas traducciones y la vinculación del traductor con la sede gallega obligaban a plantearse, al menos como posibilidad, que hubiera quedado algún testimonio manuscrito de la época en las bibliotecas de aquella ciudad gallega. Y así, emprendida la búsqueda, topamos con la copia mencionada de la que aquí damos noticia. Asi pues, el propósito de esta nota es, en primer lugar, dar a conocer este nuevo testimonio de Séneca en castellano. En segundo lugar, pondremos en relación el códice compostelano con el resto de las copias conservadas con el fin de trazar una aproximación provisional al ám-

$R F E$, LXXXI, 2001, 1. $0^{\circ}-2^{\circ}$, págs. 137-163 
bito de lectura de estas versiones. Por último, trataremos el espinoso asunto de la transmisión textual de la colección. Antes, sin embargo, parece necesario detenese a valorar sucintamente la difusión de los llamados $L i$ bros de Séneca.

Como es de sobra sabido, bajo tal título circuló una colección de obras del filósofo cordobés, unas debidas realmente a su pluma y otras atribuidas a él en el transcurso de la Edad Media, que fueron vertidas al castellano por Alfonso de Cartagena en la década de 1430. Sólo de las Siete Partidas y de un puñado de crónicas han Ilegado hasta hoy un mayor número de testimonios manuscritos de obras en prosa '. En realidad, en uno y otro caso la abundancia de copias es indicio de que las obras que transmiten tuvieron un tipo de lector muy determinado: aquel que poseía un cierto status social y los medios económicos suficientes para encargar la elaboración de copias de factura más o menos lujosa, que se custodiaban en una biblioteca. La vinculación con los medios nobiliarios, eclesiásticos y universitarios suponía que los códices producidos fueran de cierta calidad -tal y como observamos en los que nos han transmitido los Libros de Séneca-, así como su manejo y custodia en un espacio adecuado para tales propósitos (la cámara

\footnotetext{
1 De la recopilación legal alfonsí han sobrevivido casi ochenta manuscritos. De entre las crónicas, son aquellas que abarcan los reinados más conflictivos desde el punto de vista dinástico las que mayor interés parecen haber despertado. Asi, de la Crónica de Enrique $\mathrm{KV}$ de Enríquez del Castillo se conservan nada menos que 110 testimonios. No parece tampoco casual que le sigan en importancia numérica la crónica que dedicó a este reinado Alfonso de Palencia, con casi setenta manuscritos, y la Crónica de los Reyes Católicos de Hernando de Pulgar, con más de una cuarentena. La mayor extensión de la lectura en el siglo xv entre las clases nobles y la burocratización del aparato administrativo del estado, que lleva a convertir el estudio de las leyes, pero también el conocimiento de la historia en condición sine qua non para acceder a un puesto de funcionario público en tiempos de los Reyes $\mathrm{Ca}$ tólicos, explican que las crónicas de ese período gozaran de una divulgación mayor que la que se deduce de las grandes crónicas de la centuria anterior, pese a la calidad literaria y el interés político del contenido de éstas: ninguna de las compuestas por Pero López de Ayala ha sido transmitida en más de una veintena de códices frente a los casi cuarenta que merecieron algunas (las dedicadadas a Alfonso X y Fernando IV) de Ferrán Sánchez de Valladolic, cuyo éxito ha de explicarse por lo que su obra tiene de prolongación y renovación de la escuela historiográfica alfonsí (sobre este punto, véase F. Gómez Redondo, Historia de la prosa medieval castellana, Madrid, Cátedra, 1998, vol. I, págs. 965-80) y por la vigencia que esta última conservó entre las clases lectoras de finales de la Edad Media, que vieron en el corpus reunido por el Rey Sabio una summa de conocimientos sobre su pasado, el nacioral o patrio, y el clásico o de tradición occidental. Buena prueba de ello es también el número de testimonios cuatrocentistas - casi cuarenta- de las distintas partes de la General Estoria.

Los datos proceden de la magna Bibliografia Española de Textos Antiguos (BETA), de Ch. B. Faulhaber, A. Gómez Moreno, A. Moll Dexeus y A. Cortijo Ocaña, incluida en PhiloBiblon, The Bancroft Library, University of California, Berkeley, 1999. Nos hemos servido de la versión electrónica disponible en la red (http://sunsite.berkeley.edu/PhiloBiblon), núm. 4, actualizada en diciembre de 1999.
} 
privada del poseedor, una biblioteca capitular o privada, etc.). Todo ello, aunque no era garantía de perdurabilidad, incrementaba de modo muy notable las posibilidades de supervivencia del manuscrito. En el caso de las crónicas a las que nos referíamos antes y las versiones de Séneca, fue sobre todo su lectura fuera de los ámbitos populares -que no necesariamente nobiliarios, como tendremos ocasión de comprobar- lo que garantizó la pervivencia de tan alto número de códices hasta el renacimiento, época en la que el grueso de las colecciones nobiliarias y universitarias más importantes está en su mayor parte ya formado; y así, los libros o bien se conservaron como parte de los mayorazgos instituidos entonces (cuando se dio esta circunstancia) o bien pasaron a engrosar alguna de las reales bibliotecas, lo que evitó que los fondos se dispersaran, como sucedió con tantos otros, disgregados en ventas sucesivas sobre todo a partir del siglo XVII ${ }^{2}$. Por consiguiente, referirse a la cantidad de copias conservadas de las versiones de Cartagena es un indicio que no puede mencionarse sin más, para arrumbarse a continuación, como si su interpretación fuera obvia y hubiera de implicar una difusión que no necesitara de mayores precisiones. Si de un lado su inclusión entre las lecturas de nobles y caballeros de medio pelo, letrados y otras gentes con inclinaciones culturales son razón fundamental que explica en buena medida la cantidad de testimonios que nos han llegado, de otro las causas de tal inclinación a poseer una copia de Séneca en castella-

\footnotetext{
${ }^{2}$ Así ha sido anotado también para los incunables: "Por otra parte, ciertos textos incunables se guardan en docena de ejemplares porque interesaban a los nobles, cuyas bibliotecas se conservan intactas hasta el siglo XIX y muchas hasta hoy día" (Ch. Faulhaber, "Las bibliotecas españolas medievales", en Pensamiento medieval hispano. Homenaje a Horacio Santiago-Otero, coord. de J. Soto Rábanos, Madrid, CSIC - Junta de Castilla y León - Diputación de Zamora, 1998, vol. 1, págs. 785 800, cit. pág. 785). Sobre el paradero actual de las colecciones más importantes de incunables, véase J. Martín Abad, Los incunables de las bibliotecas españolas, Valencia, Vincent Garcia Editores, 1996. Notemos, sin embargo, que la difusión impresa de los Libros de Séneca es relativamente menos importante de la que gozó en manuscrito si se comparan las cinco ediciones de las que fue objeto entre 1491 y 1560 frente a la de otras obras compuestas en el siglo xv: 14 veces se reeditó la Crónica de Fernón González, 26 las obras de Juan del Encina, 32 las del Marqués de Santillana, 37 las de Juan de Mena, 28 las de fray Ambrosio de Montesino, 35 la Celestina, 25 las de Diego de San Pedro, 22 las de Diego de Valera y 21 las de Alonso de Madrigal. Dejando de lado estos dos últimos casos, puede comprobarse que en la imprenta triunfa la literatura propiamente dicha (poesía y prosa de ficción). Si limitamos la comparación a otras versiones de textos clásicos, entonces las de Séneca no sajen tan mal paradas: Quinto Curcio es objeto de dos impresiones y Esopo de seis. Tomo los datos de J. Simón Díaz ("La li* teratura medieval castellana y sus ediciones españolas de 1501 a 1506", El libro antiguo español. Actas del primer Coloquio Internacional, Madrid, 18 al 20 de diciembre de 1986 , ed. de $M^{a}$ L. López-Vidriero y P. Cátedra, Madrid, Universidad de Salamanca - Biblioteca Nacional de Madrid - Sociedad Espanola de Historia del Libro, 1988, págs. 371-381) y T. Beardsley, Hispano-classical translations: printed between 1482 and 1699, Pittsburgh, Duquesne University, 1970.
} 
no han de ser aclaradas. Mientras salta a la vista la raíz del interés de cualquier noble y del grupo entero de los letrados, leguleyos y demás funcionarios al servicio de la administración por la gran recopilación legal del reino que representó durante centurias Las Partidas o por una crónica como la del reinado de Entique IV, donde se da noticia de un cambio de dudosa legitimidad en la línea dinástica, no sucede así con la obra moral del filósofo estoico.

Quien mejor ha estudiado este aspecto de la cultura hispánica desde una perspectiva general, Karl Blüher ${ }^{3}$, rastrea la presencia de Séneca en la literatura de finales de la Edad Media, concluyendo que donde más se deja notar su huella es en la poesía de corte moral de los grandes poetas del siglo XV. No podía ser de otro modo, pues la poesía cancioneril constituye el lugar obvio donde buscar la influencia del filósofo estoico debido, sobre todo, al sesgo que predomina en los dezires y otras composiciones políticas y morales, pero, qué duda cabe, también por la condición de sus autores, contemporáneos del' traductor castellano. En cambio, el estudioso alemán deja de lado las obras en prosa - narrativas y didácticas-, así como la producción poética de autores cuyo nombre no estuvo vinculado al de Cartagena. Resta, pues, todavía aclarar cuáles son las líneas de recepción del pensamiento de Séneca y de su prosa en el Cuatrocientos peninsular, aunque contamos con una importante contribución para el área catalana, la de T. Martínez Romero ${ }^{4}$. Para ello, hay que insistir en la doble vía que consiste, de un lado, en estudiar de modo pormenorizado las versiones y, de otro, en buscar, mediante atenta lectura de las obras originales de la época, vestigios de la lectura de Séneca. Sólo de esta forma podrá calibrarse verdaderamente la evidencia manuscrita. En otras palabras: en el caso de la difusión de Séneca en el Cuatrocientos castellano falta mucho aún para completar la tarea, iniciada de manera ejemplar por Karl Blüher, de dar a conocer y evaluar cada una de las copias manuscritas. La tarea no es tan sencilla como puede parecer, ya que, como nos muestra la experiencia, siempre pueden aparecer nuevos manuscritos, enterrados en el olvido de bibliotecas poco frecuentadas; lo cual, también es de ley decirlo, constituye un aliciente para los investigadores. Además, no basta con dar noticia de esas copias, sino que, más importante aún, es preciso describirlas para facilitar a otros su inclusión en un cuadro más general, en este caso, el de la transmisión material y textual de las versiones de Séneca por

\footnotetext{
${ }^{3}$ K. Blüher, Séneca en España, Madrid, Gredos, 1983, cap. 2.

4 T. Martínez Romero, Un clàssic entre clàssics. Sobre traduccions i recepcions de Sèneca a l'época medieval, València - Barcelona, Institut Interuniversitari de Filologia Valenciana - Publicacions de l'Abadia de Montserrat, 1998.
} 
Cartagena intentando identificar sus lectores, pero tratando de evitar simplificaciones excesivas ${ }^{5}$. Comencemos por seguir el hilo que conecta al traductor con Santiago de Compostela, donde se encuentra el códice objeto de nuestra atención.

Alfonso de Cartagena fue deán de Santiago desde mediados de 1415 hasta $1435^{\circ}$. En las fechas en que ocupó este cargo, no había aún actas capitulares; sin embargo, la labor de búsqueda en los archivos catedralicios emprendida por José António Souto y Maria Mercè López Casas ha rendido frutos positivos. Ambos investigadores han podido encontrar, en un tumbo del archivo catedralicio, documentos que recogen algunas sesiones del cabildo presididas por el propio deán Alfonso de Cartagena. En este sentido, a pesar de que el contenido de los documentos no arroja luz sobre la vida de don Alfonso, aporta algún dato revelador. Hasta la fecha se desconocía en qué momento fue nombrado por Benedicto XIII para ocupar el deanato de Santiago, por lo que se aventuraba la fecha de 1415 o principios de $1416^{7}$. Ahora puede asegurarse que el 5 de agosto de 1415 ya era deán de la catedral

\footnotetext{
${ }^{5}$ Con todo, se deben tomar precauciones para no caer en espejismos. La primera, claro, deberia ser consultar el catálogo citado en nota anterior. Cualquiera de sus versiones, hasta la más antigua, habría evitado "descubrimientos" como el del ms. 38 (OI. 97) de la Biblioteca Menéndez y Pelayo de Santander (M. Gurruchaga, "Algunas observaciones acerca de los Tratados de Séneca traducidos por Don Alonso de Cartagena (Ms. 37 BMP)", Faventia, 19/2, 1997, págs. 131-40, que además lo cita por error en el resumen que antecede el artículo como ms. 37), incluido con esa signatura ya en K. Blüher (ob. cit., [1968] 1983, pág. 134, n. 67), en $B O O S T^{3}$ (Ch. Faulhaber, A. Gómez Moreno, D. Mackenzie, J. Nitti y B. Dutton, Bibliography of Old Spantish Texts, Madison, The Hispanic Seminary of Medieval Studies, 1984) y versiones posteriores (BETA) incluidas en PhiloBiblon, en M. Morrás ("Repertorio de obras, manuscritos y documentos de Alfonso de Cartagena (ca. 1384-1456)", Boletín de la Asociación Hispánica de Literatura Medieval, 5, 1991, págs. 215-248, Cuadernos bibliográficos $\mathrm{n}^{0}$ 4) y en R. M" Blasco Martínez ("Los códices del siglo XV de la Biblioteca de Menéndez Pelayo", en El libro antiguo español Actas del segundo Coloquio Internacional Madrid, I8 al 20 de diciembre de 1986), ed. de $\mathrm{M}^{\mathrm{a}} \mathrm{L}$. López-Vidriero y P. Cátedra, Madrid, Universidad de Salamanca - Biblioteca Nacional de Madrid - Sociedad Española de Historia del Libro, 1992, vol. II, págs. 97-122). La consulta de cualquiera de ellos hubiera evitado la inclusión de errores como citar en la lista de testimonios de las obras de Séneca el ms. 303 de la Biblioteca de Santa Cruz (Valladolid), que contiene la obra de Guillermo Peraldo, afirmar que el códice santanderino es uno de los más completos de los conocidos porque incluye "más de setenta tratados" (sic) y que sólo se conocen once manuscritos cuatrocentistas que nos hayan transmitido las versiones de Cartagena, o que el códice santanderino puede haber pertenecido al rey porque se le menciona en el prólogo (cf. M. Gurnuchaga, ob. cit., págs. 134-36), icómo si no lo hicieran los restantes testimonios y las ediciones!

6 Véase A. López Ferreiro, Historia de la Santa A. M. Iglesia de Santiago de Compostela, Santiago de Compostela, Imp. y Enc. del Seminario Conciliar Central, 1904, vol. VII, y S. Portela Pazos, Decanologio de la S. A. M. Iglesia Catedral de Santiago de Compostela, Santiago de Compostela, Impr. y Enc. del Seminario Conciliar, 1944.

${ }^{7}$ A. López Ferreiro, ob. cit., vol. VII, págs. $137-138$, y L. Serrano, Los conversos $D . P Q-$ blo de Santa Maria y $D$. Alfonso de Cartagena, Madrid, Patronato Marcelino Menéndez Pelayo, 1942, págs. 122-123.
} 
de Santiago (tumbo E, folio 9v), en sustitución de Antonio García. Alfonso de Cartagena conservó el cargo de deán de Santiago después de recibir el siguiente beneficio eclesiástico que le fue concedido, una canonjía en Burgos ${ }^{8}$. El prestigio del que gozaba la sede gallega explica que todavía en los años de 1430-1431 siguiera empleando ese título para identificarse, con preferencia a los restantes cargos que habia ido recibiendo sucesivamente en años posteriores. De hecho, es en su calidad de deán de la sede compostelana como figura al frente de sus versiones de Cicerón y los primeros tratados de Séneca, según testimonian las rúbricas de algunos de los códices que han transmitido estas obras ${ }^{9}$, algo natural si se tiene en cuenta que el puesto de deán queda por debajo sólo del de obispo y que la sede de Santiago era una de las de más prestigio. Y en efecto, sólo su ascenso al obispado de Burgos, a finales de 1439 o principios de 1440 , le haría renunciar al preciado puesto de Santiago. Pese a ello, su paso por la sede compostelana como deán no parece haber pasado de ser nominal. Es posible que residiera en la capital gallega entre 1416 y 1420 , y que volviera en algún viaje esporádico, como los que realizó en 1423 y en $1426^{10}$, pero, con todo, a partir de 1420 , residió en Segovia y, sobre todo, en Burgos, ciudad de origen de los Santa Maria, que vuelve a ser su centro vital. Allí retorna siempre tras los numerosos viajes que lleva a cabo y que le obligan a prolongadas ausencias debido a sus funciones de embajador (en Portugal, entre 1420 y 1423, y en 1427; en Basilea, entre 1434 y 1439) y a su condición de miembro del Consejo real (que le obligó, por ejemplo, a seguir a Juan Il a Andalucía durante la campaña con-

\footnotetext{
${ }^{8}$ L. Serrano, ob. cit., págs. 123-24.

9 Por ejemplo en BNM mss. 8830, 9613; Esc. T-III 7; Bib. Patacio II-561. BNM 9613 está fechado en 1461. Este dato permite datar todas las obras en las que todavía no se le atribuye el cargo de obispo como anteriores a 1440, pero ello no quiere decir que el manuscrito donde la rúbrica le designa como deán sea también anterior a ese año, como parece suponer $\mathrm{O}$. T. Impey ("Alfonso de Cartagena, traductor de Séneca y precursor del humanismo español", Prohemio, 3, 1972, págs. 472-494, especialmente pág. 475), aunque en última instancia el arquetipo del que procedan sí lo sea. En cualquier caso, está claro que cuando se menciona a don Alfonso como obispo de Burgos, es obligado retrasar la fecha de composición del códice en el que así figura post 1440 en lugar de insistir, precisamente, en lo temprano de su cronología, como sucede con el manuscrito de la Biblioteca Menéndez y Pelayo 38, puesto que aurque "sus caracteristicas codicológicas y paleográfjcas" señalen "inequívocamente" a la primera mitad del siglo $\mathrm{XV}$, "quizás finales de los treinta, inicio de los cuarenta de la centuria" (M. Gurruchaga, ob. cit., pág. 134), el hecho es que los datos externos hacen imposible esa datación. En efecto, por mucho que así sean los rasgos codicológicos del manuscrito en cuestión, la mención de Cartagena como obispo de Burgos nos proporciona una fecha a quo para ellos (1440 como máximo); y al contrario: que otros conserven el antiguo título bien puede ser resultado de los hábitos conservadores del copista en cuestión, que transcribió ad pedem la rúbrica de un manuscrito anterior.

${ }^{10}$ Véanse respectivamente L. Serrano, pág. 123 y F. Cantera Burgos, Alvar Garcia de Santa Maria y su familia de conversos, Madrid, Instituto Arias Montano, 1952, pág. 220.
} 
tra Granada de 1430-1431) ${ }^{11}$. Según los documentos vistos por los citados investigadores (un total de 24, en el tumbo E), que abarcan desde el 5 de agosto de 1415 hasta el 2 de octubre de 1422, cuando Cartagena no presidía el cabildo, lo hacía en su nombre un vicario, cargo desempeñado sucesivamente por Joan Martís de Noia, Alfonso Fernández de León y Fernán Rodrigues de Betanços. La mayor parte de las veces actúa uno de ellos en el desempeño de las funciones que le correspondían como deán a don Alfonso, lo que no es de extrañar, dados los cargos que simultaneó con el de Santiago: deán de Segovia, canónigo de Burgos, refrendario del Papa, refrendario del rey y su capellán, oídor de la Audiencia Real, miembro titular del Consejo Real y embajador del rey en la corte portuguesa. Además, el propio Cartagena en su testamento revela que además de en Burgos, tuvo su domicilio en Segovia, que le sirvió de residencia "más de continuo que la de Compostela por la situación de la ciudad, que no es tan remota" ${ }^{12}$. En 1456 , cuando ya anciano emprende peregrinación a Compostela con el fin de ganar el jubileo, habian transcurrido por lo que parece treinta años sin pisar suelo gallego ${ }^{13}$. El ilustre prelado murió en el viaje de vuelta, en Villasandino (Burgos).

Si su presencia física en la ciudad gallega no fue muy prolongada, ha de señalarse, en cambio, que Cartagena mantuvo un doble y estrecho vínculo con la sede compostelana, lo que explica que el archivo de la catedral y restantes bibliotecas de la diócesis conserven documentos relacionados con sus actuaciones ${ }^{14}$, así como manuscritos de obras cuya composición corres-

\footnotetext{
"Cf. L. Serrano y F. Cartera Burgos para estas referencias. Una síntesis en la que se precisan algunos datos etróneos, en M. Morrás, Las traducciones de Cicerón de Alfonso de Cartagena, Colecc. de tesis doctorales en microfichas, Bellaterra, Universidad Autónoma, 1993, capitulo 1.

12 F. Cantera Burgos, ob. cit., pág. 437.

13 Ibidem, pág. 222.

14 Además de los textos conservados en el tumbo E, J. A. Souto y M. M. López Casas han localizado otros dos documentos más (carpeta 19, núms. 27 y 37): uno portugués, que ya diera a conocer S. Portela Pazos (ob. cit., pág. 151), sobre el pago de los votos de Ríba de Coa a la catedral compostelana; y otro que como el anterior, aunque no tiene grafia portuguesa, nos habla de la estancia de Alfonso de Cartagena en Portugal. El primero fue editado fragmentariamente por Portela Pazos; se incluye aquí de nuevo la parte más interesante del documento, por lo que a Cartagena se refiere, ya que la versión citada contiene varios errores: "In nomine Domini, amen. Sabham quantos este pubrico estromento virem que aos quatorze dias de Janeiro, ano do nacimento de nosso senhor salvador, Jhesu Christo, de mil e quatrocentos e vinte e seis anos, ena villa de Monte Moor o Novo, lugar do bispado d' Evora, dentro em as casas onde pousa o doutor dom Afonso Garcia, deam das Egrejas de Santiago e de Sogoiva e ouvidor e refrendario do senhor rei de Castella e do set conselho e seu embaixador, que a esta sazom estava em a corte do senhor rei de Portugall, estando presente o dito deam e Joham Afonso coonigo de Santiago e de Coimbra, criado de dom Joham Garcia Manrique arcebispo que foi de Santiago, que Deus perdoe, o dito deam disse ao dito Joham Afonso que bem sabia ell como os votos e direitos de Riba de Coa pertenciam a egreja e cabidoo de Santiago". Es precisamente en la villa de Monte-Mor o Novo donde Alonso de Cartagena tradujo el De senectute de Cicerón, traducción fechada en 1422, lo que impłica que tal lugar constituiría una de sus residencias babituales en tierras portuguesas.
} 
ponde al periodo posterior a 1426 , último año en el que se ha podido documentar su presencia física en Santiago antes de la peregrinación a la que nos referiamos antes. El vínculo era de tipo espiritual y cultural. De un lado, Alfonso mostró siempre una gran devoción por la figura del Apóstol, manifiesta en las referencias a su milagrosa intervención en la batalla de Clavijo que salpican su producción historiográfica ${ }^{15}$ y en la manda a la catedral que dejó en su testamento ${ }^{16}$. De otro, la familia Santa María mantuvo importantes lazos políticos y culturales con los sucesivos arzobispos y restantes cargos eclesiásticos de Santiago. Téngase en cuenta, por ejemplo, que la sede de Plasencia, de la que Gonzalo, el hermano mayor de don Alonso, fue obispo, y al que éste consideraba su mentor, dependia de Santiago ${ }^{17}$. Además, durante el siglo xv el puesto de arzobispo de Santiago fue ocupado por vástagos de varios linajes asentados en el norte de Castilla, como los Manrique y los Acuña, con los que Cartagena mantuvo una relación política y literaria notable ${ }^{18}$.

\section{Descripción del códice del convento de SAN Francisco}

En la biblioteca del convento de San Francisco (Santiago de Compostela) apenas se conservan códices medievales de contenido literario. Como ya hemos mencionado, la falta de un catálogo que permita una búsqueda sistemática hace dificil explorar los fondos allí custodiados. Tampoco es fácil averiguar su procedencia: como otros conventos, su biblioteca fue expoliada en los años que siguieron a la desamortización de Mendizábal; por otro lado, manos piadosas que habían escondido volúmenes de esta y otras bibliotecas conventuales no dudaron en depositarlos aquí y en otras instituciones religiosas, una vez pasados los años de mayor agitación política. Este parece ser el origen de un códice del siglo $\mathrm{XV}$, de factura no lujosa que contiene las traducciones de Séneca y que hemos podido localizar.

\footnotetext{
E] segundo documento localizado, copia compostelana de la misma época de un original redactado en Lisboa, nos sitúa nuevamente al deán de Santiago en ese reino durante el año de 1425 . Este texto ofrece igualmente datos concretos sobre su residencia y entorno humano en la capital. Se aloja en casa de Pedro Garcia (tal vez su hermano u otro pariente) y va acompañado de sus familiares: Ruj Vasques Leitom, "cavaleiro", Luis de Liom, Joam Ferrejra y Joam Lourenço, "capelam". Quizás pueda surgir algún otro documento que nos proporcione más ínformación sobre la fígura de don Alfonso, datos que ofreceremos en un futuro si resultan ser de interés para conocer un poco más la vida y obra de Cartagena.

15 L. Serrano, ob, cit. págs. 223-224.

${ }^{16}$ F. Cantera Burgos, ob. cit., pág. 455.

17 lbidem, pág. 413.

${ }^{18}$ M. Morrás, Imágenes de vida y muerte. En torno a las "Coplas por la muerte de su padre" de Jorge Manrique, Londres, Queen Mary \& Westfield College, en prensa.
} 
El volumen permanece fiel a las pautas habituales seguidas en otros ejemplares que contienen las versiones de Séneca debidas a Alfonso de Cartagena; volveremos a este punto más adelante. Sin llegar a ser un ejemplar de lujo o siquiera semilujoso, se trata claramente de un libro realizado para una biblioteca con ciertos medios. La encuadernación es de cuero repujado sobre tabla, con ornamentación de tipo mudéjar consistente en figuras geométricas triangulares con la figura de un dragón en su interior, todavía fácilmente visibles a pesar de que la superficie aparece desgastada por el uso y quizá por una azarosa conservación; los dos broches metálicos con los que se cerraba el volumen están actualmente rotos. En el lomo se lee la signatura $17732^{19}$. En el interior, en una ficha alguien ha identificado erróneamente al autor como "Arvallo"; una evidente mala lectura de "aluçillo" que es lo que dice el texto original (fol. 91v), y que se refiere, claro está, al dedicatario de la epístola de Séneca traducida bajo el título de Las siete artes liberales.

Las páginas del códice también están álgo deterioradas debido a que el papel no es de muy buena calidad; al trasluz son visibles numerosos y gruesos corondeles. Las manchas de humedad dificultan la lectura del margen inferior a partir del folio 174 y hasta el final. La densidad de la escritura, la escasa calidad del papel y su estado impiden descifrar la imagen de las filigranas que se aprecian en algunos folios. Una de las dos hojas de guarda (la otra falta) ha sido aprovechada para copiar en latín, por una mano del siglo XVI, sentencias extractadas de Séneca. Esto último parece apuntar a que las versiones vernáculas, aunque en principio destinadas a lectores que ignoraban el latín, fueron empleadas con frecuencia como ayuda para la lectura de los originales latinos; otros indicios en este sentido pueden rastrearse en códices cuatrocentistas que han transmitido textos clásicos en traducción ${ }^{20}$.

Las medidas del códice son $278 \times 260$. El texto aparece dividido entre el texto y las glosas, marcados ambos en la caja de escritura a lápiz, con los extremos señalados con un punzón. Caja externa: 150x96; caja interna: $135 \times 90$. Número de folios: 197 .

A diferencia de la mayor parte de los testimonios que nos han transmitido las versiones de Séneca por Cartagena, el texto está distribuido en dos

\footnotetext{
${ }^{19}$ Aunque no parece propia de un depósito antiguo, ignoramos si tal signatura es válida hoy, pues no tuvimos acceso a ningún tipo de catálogo o fichero en el Convento de San Francisco, donde se nos informó que los manuscritos carecian de signatura. Por ello, y con mayor motivo, agradecemos las facilidades que se nos dieron para la consulta y estudio del códice.

${ }^{20} \mathrm{M}$. Morrás, "Traducción de los clásicos y traducción textual", en Humanismo y pervivencia del mundo clásico. Homenaje al profesor Luis Gil, ed. de J. $\mathrm{M}^{\mathrm{a}}$ Maestre Maestre, J. Pascual Barea y L. Charlo Brea, Cádiz, Universidad de Cádiz, 1997, vol. II, págs. 531-538.
} 
columnas, lo que denota un formato escolar frente a la disposición a renglón tirado, más frecuente en los códices influidos por el humanismo italiano. Las glosas están dispuestas alrededor de la caja central, como ocurre en la mayor parte de los manuscritos glosados de esta época. La tinta es de óxido de color sepia alternando con calderones y rúbricas en rojo. Letras capitales miniadas. Numeración original romana en el margen superior derecho. Falta el primer folio, de modo que el texto comienza en el fol. 2. Los cuadernos se componen de doce folios; son, por tanto, seniones. La estructura es como sigue: $a^{17}$ (falta el primer fol.) $+b^{12}+c^{12}+d^{11}$ (falta el primer folio del cuaderno) $+\ldots . .+\tilde{n}^{8}$ (faltan los cuatro últimos folios) $+o^{12}$. Se conservan los reclamos al final de cada cuaderno, situados en el centro inferior del folio.

Abundan las probatoria pennae en diferentes manos de los siglos xv y XVI: "al muy $\mathrm{m}<\mathrm{a}>\mathrm{g}<$ nifico $>$ y Reb $<$ erend $>0 \mathrm{~S}<\mathrm{eñ}>$ or el $\mathrm{s}<$ eñ $>$ or arcediano de molyna", fol. 2r; "Este mj $s<e \tilde{n}>$ or Roma(?) p<ara $>$ alli $q<u e>v<$ uestra $>\mathrm{m}<$ erced $>$ me mandares", fol. 17r; "antonio de aguirre", "juan del campo", fol. 19r; ""Juan garcia", "juan vazquez", "juan de Pulgar". En el fol. 11lv se lee escrito por una mano del siglo $\mathrm{xv}$ "alonso de tapya" y en el fol. 114r, en un recuadro: "alonso de tapya traslado este libro". No obstante, resulta dificil dilucidar si se trata efectivamente del copista o de una prueba de pluma, pues el lugar donde aparece la frase, en el hueco dejado en el margen superior por el texto, no es el habitual para declarar la autoría de la copia.

Los títulos que integran el volumen son los siguientes (citamos las rúbricas iniciales y finales que van en tinta roja y también el incipit y explicit de cada texto; incluimos la foliación en cada caso, porque a menudo no coincide el folio en que aparece la rúbrica y el texto):

1) fols. $\mathrm{ij}^{\mathrm{r}}-\mathrm{xij}^{\mathrm{v}}$ : [De la vida bienaventurada $=$ De vita beata $]$

Incipit (f. 2r): -za \& desde aq<ue $>1$ q<ue $>$ vsa de paño de oro fasta aq $<$ ue $>1 \mathrm{q}<\mathrm{ue}>$ se viste de lienço crudo

Explicit (f. 62r): pienso yo $\mathrm{q}<\mathrm{ue}>$ el $\mathrm{q}<\mathrm{ue}>$ esto dize non loa al nauegar ante me[ ]vieda el ancorra pues en todas las mares por la mayor $\mathrm{p}<\mathrm{ar}>\mathrm{te}$ sobreujene algu $<\mathrm{n}>$ as vezes tormenta

Rúbrica final (f. 62v): aquj se acaba el $\mathrm{p}<\mathrm{ri}>$ mero libro de Seneca $\mathrm{q}<\mathrm{ue}>$ llama dela vida bien aventurada

2) fols. Ixij ${ }^{2}-$ lxxviij $^{\mathrm{v}}[$ De las siete artes liberales $=$ Epistola ad Lucilium, LXXXVIII]

Rúbrica inicial (f. 62v): aquj comiença el segundo libro de Seneca q<ue>se Hama de las siete artes liberales en el $q<$ ua $>1$ muestra $q<u e>$ non ponen en $\mathrm{n}<$ uest>ro coraçón la virtut mas $\mathrm{q}<\mathrm{ue}>$ lo aparejan $\mathrm{p}<\mathrm{ar}>a$ la rresçibir 
Incipit (f. 63r): Deseas saber $\mathrm{q}<\mathrm{ue}>$ es lo $\mathrm{q}<\mathrm{ue}>$ paresçe de los estudios liberales

Explicit (f. 78v): diziendo $\mathrm{q}<\mathrm{ue}>$ non solamente non sabemos nada mas avn dixieron $\mathrm{q}<\mathrm{ue}>$ non podemos saber $\mathrm{q}<\mathrm{ue}>$ non sabemos nada Rúbrica final (f. 78v): aq<ui> se acaba el libro delas siete artes liberales en $\mathrm{q}<\mathrm{ue}>$ seneca mostro fablando de cada vna dellas $\mathrm{q}<\mathrm{ue}>$ non ponen en $n<u e s>$ tro coraçon la virtut mas $q<u e>10$ aparejan $p<a r>a$ la rresçebir

3) fols. Ixxviij ${ }^{\mathrm{v}}-\mathrm{xci}^{\mathrm{v}}$ : [De amonestamientos $e$ dotrinas $=$ De legalibus institutis, pseudo-Séneca]

Rúbrica inicial (f. 78v): aquj comjença el terçero libro de seneca que se llama de amonestamjentos \& dotrinas enel qual ay siete capitulos enlos $\mathrm{q}<\mathrm{ua}>$ les se contienen çiento \& sesenta \& tres dotrinas. capitulo $\mathrm{p}<\mathrm{r}>\mathrm{me}-$ ro dot $<$ ri $>$ na vna

Incipit (f. 79r): Non ay cosa $\mathrm{ta}<\mathrm{n}>$ mortal alos jngenjos humanos como la luxuria

Explicit (f. 91v): esto guarda muchó q<ue> no sea tu pobreza enbidiosa njn sea tu abstinençia delas viandas suzia \& vil

Rúbrica final: aq $<\mathrm{ui}>$ se acaba el $\left({ }^{\wedge} \mathrm{q}<\mathrm{ua}>\right)$ terçero lib $<\mathrm{r}>\mathrm{o}$ de seneca de amonestamientos \& dotrinas

4) fols. $\mathrm{xcj}^{\mathrm{v}}-\mathrm{cxxj}^{\mathrm{r}}$ : $[$ De la providençia de Dios $=$ De constantia sapientis]

Rúbrica inicial (f. 91v): aq<ui> comiença el q<ua>rto libro de Seneca $\mathrm{q}<\mathrm{ue}>$ esc $<\mathrm{r}>\mathrm{vjo}$ a huçillo el $\mathrm{q}<\mathrm{ua}>1$ se llama dela proujdençja de dios trasladado del latin en lenguaje castellano por mandado del muy alto \& muy poderoso $\mathrm{p}<\mathrm{ri}>$ nçipe rrey \& señor $\mathrm{n}<$ uest>ro señor el rrey don ioh $<a>n$ de castila \& de leon el segundo. por ende el prologo fabla con $<e>$ l. prologo enla traslaçio $<\mathrm{n}>$

Incipit (f. 92r): Quant dulçe es la çiençia o muy catolyco rrey avn aq $<$ ue $>$ I ] ]lo siente $\mathrm{q}<\mathrm{ue}>$ nunca apre $<\mathrm{n}>$ dio ca deleyta el ver deleyta el oyr deleyta alas vezes los otros sentidos

Explicit (f. 120v): por $\mathrm{q}<\mathrm{ue}>$ non avedes verguença de temer luenga mente lo $\mathrm{q}<\mathrm{ue}>\tan$ ayna se pasa

Rúbrica final (f. 121r): aq<ui $>$ se acaba el $\mathrm{q}<\mathrm{ua}>\mathrm{rto}$ libro de seneca dela proujdençia de dios

5) fols cxxj ${ }^{\mathrm{T}}$-cxcij] ${ }^{\mathrm{v}}$ : [Copilación de algunos dichos de Séneca $=$ Tabulatio et expositio Senecae de Lucas Manelli]

Rúbrica inicial (f. 111r): aquj comjença el q<ui>nto libro de Seneca en $q<u e>$ trata como enel sabidor non cae jnjuria njn ofensa alguna todos estos capitulos $\mathrm{q}<\mathrm{ue}>$ se siguen fueron sacados dela copilaçion del alfabeto. capitulo $\mathrm{p}<\mathrm{r}>\mathrm{m}<\mathrm{er}>0$

Incipit (f. 121r): Seneca enla epistola sesenta \& nueue dize $\mathrm{q}<\mathrm{ue}>$ los $\mathrm{q}<u e>\mathrm{q}<\mathrm{ui}>$ eren $\mathrm{q}<\mathrm{ui}>\operatorname{tar}$ de fiel amor $\mathbf{q}<\mathrm{ue}>$ deuen escusar de ver \& oyr 
Explicit (f. 192v): el atamj<en>to delas manos significa $q<u e>1 a$ orden del benefiçio $q<$ ue $>$ pasa por las manos se torna alas manos del $q<u e>$ lo da

Rúbrica final: [el texto queda trunco por la falta de los folios finales, por lo que no hay rúbrica final]

\section{LOS LIBROS DE SENECA EN EL CÓDICE COMPOSTELANO Y SU FILIACIÓN}

Lo primero que hay que destacar del ejemplar compostelano es su similitud formal con los restantes manuscritos que nos han transmitido las obras de Séneca en la versión de Alfonso de Cartagena. De hecho, todos ellos presentan caracteristicas codicológicas sorprendentemente uniformes, lo cual permite aproximarse al perfil del lector real que tuvieron las traducciones. También puede conjeturarse que el proceso de copia de los volúmenes tuvo lugar por préstamos sucesivos de un modelo que fue ampliado por la incorporación de diferentes títulos --aunque quizás en alguna ocasión, aunque rara, éste se vio reducido con la exclusión de algunos de ellos- pero que siempre conservó los rasgos de la mise en page del modelo inicial o arquetipo.

Sabemos, en efecto, que el tipo de lector al que iba dirigida la obra condicionaba los modos de su difusión, determinando en buena medida si se leería en un espacio cerrado (biblioteca o cámara privada) o si su destino sería rodar de mano en mano por calles y plazas; la factura (tamaño, tipo de letra, distribución en columnas) y la calidad del códice (pergamino o papel, tipo de papel, encuadernación sobre tabla o mera adición de hojas de guarda, etc.) dependian a su vez del uso que se daria al texto ${ }^{21}$. De la cuarentena de códices que contienen los Libros de Séneca, la abrumadora mayoría utilizan como soporte escriturario el papel, mientras que cinco de ellos emplean el pergamino (Ms. 38 (Ol. 97) de la Biblioteca Menéndez y Pelayo; mss. 9180, 9613 (un bifolio) y 817 de la Biblioteca Nacional de Madrid; mss. 201 y 607 de la Biblioteca Universitaria de Salamanca). El formato es asimismo muy similar: tres cuartas partes de las copias miden en torno a los $275 \mathrm{~mm}$. de alto y entre 200 y $210 \mathrm{~mm}$. de ancho ${ }^{22}$. Tam-

\footnotetext{
${ }^{21}$ E. Ruiz, "Hacia una tipología del manuscrito castellano en el siglo $\mathrm{xv",} \mathrm{Calligraphia} \mathrm{et}$ tipographia. Arithmetica et numerica. Chronologia. Rvbrica, 7, 1998, págs. 405-435; aunque cf. M. Sánchez Mariana, ob. cit., y R. Mª Blasco Martínez, ob. cit., págs. 98-100.

22 Las únicas excepciones, donde las dimensiones se apartan notablemente de estos másgenes, son un ejemplar de lujo, de gran formato (ms. 817 de la Biblioteca Nacional de Madrid, que mide $411 \times 278 \mathrm{~mm}$.) y dos copias que se distinguen del resto por su pequeño tamaño (mss. 1615 y 17803 de la misma biblioteca, que miden $193 \times 143 \mathrm{~mm}$. y $205 \times 180 \mathrm{~mm}$. respectivamente).
} 
bién la disposición de la mise en page es casi idéntica: el texto de la versión aparece a línea tirada en una mayoría de casos, siguiendo la pauta asociada a los manuscritos humanísticos de inspiración italianizante, y siempre ocupando la zona central de la página, con las glosas dispuestas alrededor a modo de marco; la relación entre ambos se establece mediante un sistema que consiste en subrayar dentro del texto la palabra glosada, palabra que en la glosa aparece enmarcada entre sendos calderones (o calderón y vírgula) y reproducida en un cuerpo algo mayor que el texto. Todos los manuscritos llevan rúbricas, alternando el bermellón y el azul o morado en los calderones; en los códices más lujosos las versales están orladas con filigranas de diseño vegetal de estilo gótico. En cuanto al tipo de letra, prevalece con mucho la gótica en sus diversas formas (libratia, cortesana, etc.), pues sólo tenemos constancia de una copia en letra humanística (ms. 1272 de la Biblioteca Nacional de Madrid), copia que, por otro lado, parece haber sido confeccionada entrado el siglo XVI ${ }^{23}$.

En esta somera descripción general puede observarse entonces que son tres los elementos entre los que existe variación: el tamaño, el soporte y la distribución del texto a dos columnas o en línea corrida. Entre ellos existe una correlación, de modo que los ejemplares más lujosos - lo que incluye a los que son de pergamino y de papel de mejor calidad— son los más grandes de tamaño (miden alrededor de $300 \mathrm{~mm}$. o superan esta medida) y copian el texto a toda plana. En este grupo se incluyen los citados manuscritos conservados hoy en la Biblioteca Nacional de Madrid (ms. 9180, que perteneció al

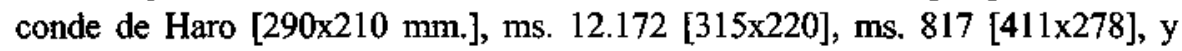
algo más pequeño $\mathrm{ms} .9613$ [280×215 mm.]), en la Universitaria de Salamanca (ms. 201 [298x232], 1813 [287×210] y 607), El Escorial (mss. L-II15 [303x217], N-III-6 [304x215]) y en la Biblioteca Menéndez y Pelayo de Santander (ms. 38 (Ol. 97) [270x210]). Este grupo, que representa algo menos del $10 \%$ del total ${ }^{24}$, estaría compuesto por códices de lujo, destinados a omamentar las bibliotecas de nobles con posibles, incluyéndose en el grupo denominado por Elisa Ruiz como "libro cortesano" 25 . Sin embargo, los res-

\footnotetext{
${ }^{23}$ Véanse M. Morrás, "Repertorio de obras, manuscritos y documentos de Alfonso de Cartagena (ca. 1384-1456)", Boletín de la Asociación Hispánica de Literatura Medieval, 5, 1991 , págs. 215-248; y Ch. Faulhaber et al., BETA en Philobiblon, sub signatura.

${ }^{24}$ A pesar del escaso número, su proporción no es reducida si lo comparamos con la que se da en el total de los manuscritos confeccionados entre 1425 y 1500 . Según BETA, tan sólo hay 39 códices en pergamino fechados en esta época de un total de casi un millar, lo que supone menos del $0,05 \%$. Hay que concluir que, a pesar de to que notamos más abajo sobre la transmisión intraestamental de Séneca, to cierto es que constituyó al mismo tiempo uno de los libros más preciados (lo que no implica necesariamente que de los más leídos) de la nobleza castellana.

${ }^{25}$ E. Ruiz, ob. cit., págs. 416-420.
} 
tantes ejemplares, con excepción de dos volúmenes de pequeño formato (Bib. Nacional de Madrid, mss. 1615 y 17803), entran en un mismo grupo, donde los códices presentan distinto grado de calidad (del casi lujoso al casi "vulgar" o "corriente"), aunque resulta dificil su clasificación si se atiende a la tipología establecida. Por un lado, pertenecerian al apartado de los "libros instructivos" dentro de la categoria de los "comientes" ${ }^{26}$ por la falta de ornamentación y la disposición ocasional del texto en dos columnas, pero el cuidado en su realización y su disposición, calcada sobre la del grupo de los códices cortesanos, permitiría situarlos más bien dentro de un grupo paralelo al de los libros "pseudo-cortesanos" ${ }^{27}$. Decimos paralelo porque si bien su formato y mise en page es idéntica a la que presentan los ejemplares de lujo, en cambio carecen de la omamentación tan característica de los volúmenes realizados para satisfacer la demanda de los burgueses acaudalados y deseosos de asimilarse en sus gustos a las clases nobles; también impide su adscripción al grupo de los libros pseudo-cortesanos el que su escritura no es de tipo cursivo. En realidad, la mayor parte de las copias de los Libros de Séneca parecen haber sido confeccionadas a partir de ejemplares "cortesanos" para la lectura y estudio de letrados y eclesiásticos de no muchas posibilidades económicas y quizá no excesivo brillo intelectual, un tipo de lector bastante desatendido en los trabajos sobre el siglo xV y que, sin embargo parece ser responsable de la elaboración y lectura de una mayoría de los códices castellanos del último cuarto de la centuria ${ }^{28}$.

Ese grupo de letrados y eclesiásticos habría tenido acceso a las versiones de Cartagena por su contacto, en calidad de familiares y empleados, con aquellos nobles entre los que circularon los textos de Séneca y que, a su vez, según puede aventurarse, se hicieron con una copia bien a partir de los ejemplares entregados al rey Juan $\mathrm{II}^{29}$, destinatario de las traducciones,

${ }^{26}$ Ibidem, págs. 419-422.

27 Ibidem, pág. 417.

${ }^{28}$ Véanse M. Sánchez Mariana, ob. cit., pág. 329, R, M ${ }^{\text {a }}$ Blassco Martínez, ob. cit., pág. 112; cf. también sobre las Flores de filosofia, M. Haro y J. C. Conde, "De nobles, eclesiásticos y libros: sobre los (verdaderos) propietarios de los manuscritos del Libro de los cien capitulos", Cultura Neolatina, 57, 1998, págs. 149-164.

Así se desprende también de la producción literaria, como hace notar G. Cappelli: "la indudable movilidad social de esta época favorece la formación de una burocracia "burguesa", o sea, no noble y lega, que necesita de medios cognoscitivos, herramientas culturales que permiten desarrollar su trabajo, que ya no es sólo el mero trámite administrativo..." ("El humanismo vernáculo de Juan de Lucena (estudios sobre el De vita felici)", tesis de licenciatura inédita, Bellaterra, Universidad Autónoma de Barcelona, 1999, en prensa, pág. 6 del original mecanografiado).

${ }^{29}$ De momento, se trata de una conjetura, basada en una filiación provisional de los manuscritos que tiene en cuenta en el número y disposición de los titulos que componen los códices, así como en las caracteristicas externas de éstos. Estos datos concuerdan con lo que sabemos acerca de los poseedores de algunos de los volúmenes y del proceso seguido por 
bien a partir del volumen o volúmenes que seguramente conservó para sí el traductor ${ }^{30}$. Curiosamente, son estos lectores y copistas, posiblemente "notarios, escribanos, estudiantes o simples aficionados con habilidades caligráficas" ${ }^{31}$ los que han dejado con mayor frecuencia su huella en las copias que conocemos de los Libros de Séneca. Son hombres de los que no tenemos apenas datos aparte de su nombre, pero que se confiesan al servicio de nobles que en más de una ocasión podemos relacionar directamente con

Cartagena en la traducción de los diferentes títulos. Hasta que no tengamos un stemma fiable de las versiones de Séneca y no conozcamos con cierto detalle la historia externa de los manuscritos que las han transmitido no podremos pasar de la mera hipótesis.

Mientras tanto, disponemos de suficiente información como para vislumbrar una historia textual harto compleja. El proceso de traducción se prolongó a lo largo de media década, de 1430 hasta al menos 1434, quizá más allá, y comenzó con una antología de extractos para incluir después varias obras, según sabemos gracias a las declaraciones del deán de Santiago en los prólogos (K. Blüher, ob. cit., págs. 135-142). El número variable de títulos que se incluyen en los códices parece reflejar más bien la sucesiva acumulación y reordenación de versiones antes que un proceso de selección por parte de algunos lectores que dejarían fuera de la colección algunos títulos (véase más adelante). Suponer, como se ha hecho sin aportar ningún dato en el que basarse, un proceso lineal de copia, donde "la serie de préstamos se inicia a partir del depósito realizado a Alonso de Palencia de, posiblemente, un traslado de la traducción realizada para Juan II de Trastámara, que se continuaría con el préstamo de la obra por parte de Palencia a Gutiérrez de Quijada, señor de Villagarcía de Campos" (M. Guruchaga, ob. cit., pág. 133) y de éste a una serie de nobles resulta, cuando menos, una suposición gratuita, cuando además la autora de tal afirmación va acumulando suposiciones dispares con idéntica contundencia y falta de base ( $c f$. un poco más adelante, en la pág. 136: "caso de descartarse estas posibilidades ídespués de proponer a Palencia y a continuación a Juan II como los poseedores del manuscrito], no puede dudarse [sic] de la atribución del códice al entorno de fruición y estudio aristocrático de la denominada "Escuela de Salamanca". Volveremos sobre este punto al tratar del lugar que ocupa el códice hallado en el convento de San Francisco de Santiago de Compostela en la historia textual de las versiones castellanas del filósofo cordobés.

${ }^{30}$ Sobre el que puede aventurarse que por lo general seguiría el consejo de su contemporáneo Enrique de Villena: "E eso mesmo para que lo comuniquedes a muchos por traslados, complaziendo en ello a vuestros amigos e así en utilidad común redunde. $E$ que tengades cautela d'é todavía dos oreginales, uno que de vós non partades e otro para prestar, porque algunas vezes non tornan los libros prestados; pierde por ende el fruto e uso d'ellos el que los presta sin dicha cautela" (Arte cisoria, en Obras completas, ed. P. Cátedra, Madrid, Turner, 1994, vol. I, pág. 214). Dos indicios lo señalan así. De una parte, el hecho de que hiciera depositar una copia de los Tratados de Séneca junto a otras obras propias en la Capilla de la Visitación de la catedral de Burgos, donde mandó ser sepultado (en el inventario figura con el número 10 ; cf. M. Morrás, "Repertorio de obras, manuscritos y documentos de Alfonso de Cartagena (ca. 1384-1456)", Boletin de la Asociación Hispánica de Literatura Medieval, 5, 1991, págs. 215-248 [221]. De otro, del estudio de la transmisión manuscrita de las versiones de Cicerón se deduce la existencia de tradiciones textuales que señalan la costumbre mencionada, pues una de ellas se remonta a la copia corregida que quedó en manos del traductor, mientras la otra deriva del ejemplar del destinatario -y en este caso colaborador en la traducción-, Juan Alfonso de Zamora (M. Morrás, introd. y ed. de Alfonso de Cartagena, Los libros de Tulio. De los ofiçios. De la vejez, Alcalá de Henares, Universidad, 1996, cap. III, especialmente págs. 126-133).

${ }^{31}$ M. Sánchez Mariana, ob. cit., pág. 329. 
el circulo intelectual de Juan II de Castilla: García de Paz, familiar o criado de Luis Álvaro de Paz, que formó parte de la embajada al Concilio de Basilea, copió en 1476 el códice Esc. N-III-6, ejemplar semi-lujoso, para su hijo, quien a su vez lo cedió a su señor Antonio de Velasco y Zúñiga, conde de Nieva, en Valladolid el año de 1516; Antonio de Maluenda, linaje relacionado con los Santa María con numerosos miembros al servicio de la catedral, confeccionó el manuscrito 5568 de la Biblioteca Nacional de Madrid que además utilizó para anotar las fechas significativas de su familia (nacimientos y defunciones), lo que seguramente indica que conservaba el volumen en su cámara; un tal Alonso de Torrijos firma en 1461 el ms. 9613 de esa misma biblioteca... En nuestra opinión, es importante subrayar el hecho de que estos datos, de los que se desprende una transmisión "intraestamental" de modo que los libros circulaban simultánea o sucesivamente entre los medios aristrocráticos, los letrados (universitarios, administrativos y eclesiásticos) y, en menor medida en este caso concreto, los burgueses, impiden establecer categorías rígidas sobre la difusión y lectura para algunas obras del Cuatrocientos, singularmente para las traducciones de textos clásicos que podían ser lo mismo lecturas de "entretenimiento", es decir, objeto de lectura privada en busca de deleite y provecho, que de instrucción, tanto formal (en los estudios generales y la universidad) como no reglada (la que recibian muchos nobles, hijosdalgo e incluso burgueses, de ayos particulares y escuelas concejiles) ${ }^{32}$. De acuerdo con esto, el códice compostelano -que estaría quizá equidistante entre la categoría de los manuscritos "corrientes" (por la calidad del volumen y de la caligrafía) y la de los "cortesanos" (por la sencillez y funcionalidad de su factura) - parece haber sido realizado para servir en la instrucción de jóvenes en algún convento, como lo indican la solidez de su encuadernación en un códice, por otro lado, bastante pobre en su ejecución y materiales, así como la copia de sentencias de Séneca en latín en una de las hojas de guarda y la abundancia de probatoriae pennae.

Por último, cabe preguntarse sobre la relación textual entre nuestro volumen y los restantes testimonios de los Libros de Séneca. Aunque falta aún por realizar el cotejo textual que permita trazar la filiación de las copias que han llegado hasta nosotros, se ha propuesto la agrupación de algunos de los testimonios en varias familias. Así, Blüher ${ }^{33}$ afirma que al-

\footnotetext{
32 Sobre este último aspecto y su auge en la Castilla de 1400 , véase $\mathrm{M}^{\mathrm{a}} \mathrm{C}$. Beceiro Pita ("Entre el ámbito privado y las competencias públicas: la educación en el reino de Castilla", en Pensamiento medieval hispano. Homenaje a Horacio Santiago-Otero, coord. de J. Soto Rábanos, Madrid, CSIC - Junta de Castilla y León - Diputación de Zamora, 1998, vol. I, págs. 861-886), que remite a otros estudios que interesan para esta cuestión.

${ }^{13} \mathrm{~K}$. Blüher, ob. cit., págs. $135-136$, n. 69.
} 
gunos de los manuscritos (Biblioteca Nacional de Madrid 817, 8241, 12172 y 17798; Escorial T-III-5; Biblioteca Universitaria de Salamanca II-3072) comparten con la edición un error común consistente en que la Copilación aparece con el siguiente incipit: "Aqui comiença el segundo libro de Seneca dela providencia de dios. En que se tracta como enel sabio no cae injuria ni offensa alguna. Todos estos capitulos que se siguen fueron sacados dela copilacion del alphabeto enel tractado del amor" ( $c f$. la edición de Alcalá, 1530, f. XLVIv). El error, según el parecer del erudito germano, podría haberse originado en una ordenación según la cual el primer libro de la Providencia de Dios fuera seguida de la Copilación de los dichos de Séneca, ordenación —añadimos por nuestra parte- que sería sentida anómala, aunque no se conociera la tradición medieval latina ( $c f$. infra n. 34), frente a la considerada más "normal", según la cual el segundo libro de la Providencia (en realidad, también de cualquier otro titulo) seguiría al primero $^{34}$. A este razonamiento se le puede objetar que, según Blüher ya dedujo de las referencias internas que proporciona don Alfonso sobre la labor realizada, Cartagena no tradujo los que aparecen como dos libros de la Providencia seguidos, sino que intercaló en medio la traducción de los libros De la clemencia. Es decir, que el orden que figura en este grupo de testimonios según el cual el libro primero del De la providencia precede a la Copilaçión y en ésta, por error, se adopta una rúbrica en la que se confunde el extracto y comentario debidos a Lucca Manelli con un supuesto libro II del De la providencia, parece ser resultado, primero, de invertir la disposición cronológica de las versiones, según la cual primero vendría la Copilación y después De la providencia (l) y, en segundo lugar, de pensar que lo que viene detrás de un supuesto libro I debe ser el libro Il del mismo título. Es decir, que en algún momento alguien —quizá el propio traductor, pero pudo haber sido también un copista-, decidió organizar lo que comenzaba a ser una colección de obras digamos "completas" de un

\footnotetext{
${ }^{34}$ Como es sabido (cf. K. Blüher, ob. cit, págs. 133-134), en realidad lo que en los códjces aparece como "libro segundo de la Providencia" no es tal, sino un título diferente de Séneca. El llamado en la versión libro I o Libro de la providencia de Dios es la traducción del De providentia, mientras el considerado ya en la transmisión latina medieval como libro II y titulado en la versión castellana Libro de la providencia divina corresponde a la obra que Séneca llamó De constantia sapientis. No ha de extrañar, pues, que Cartagena los tradujera como obras independientes, que lo eran, pero tampoco debe chocarnos la disposición finalmente adoptada. Ésta podria deberse, no obstante, tanto al traductor como a cualquier conocedor de la obra latina de Séneca según la organización típica en la Edad Metia, incluso a un copista que desconociendo aquella, se limitara a poner en su "orden natural" ambos libros; esto es, el segundo tras el primero. Con todo, la primera posibilidad es la más verosímil dado que el propio Cartagena dice del Libro de la providencia divina que es el "libro segundo". Por otro lado, resulta arriesgado otorgar significación a la variante "de Dios"/divira" y, además, no hemos podido comprobar todavía que tal variante aparezca en todos los testimonios.
} 
autor en versión castellana según un modelo que implicaba colocar en primer lugar los títulos de obras completas y al final las antologías de extractos. Ahora bien, al desgajar los cuadernos en los que se habían acumulado los textos de acuerdo a la secuencia cronológica de su elaboración, la última parte del, digamos de acuerdo con la tradición medieval, libro I del De la providencia sería tomado equivocadamente como el primero de la Copilación dando lugar al error detectado por Blüher. Ello colocaría al subarquetipo del que deriva esta familia en un lugar muy alto del stemma, puesto que además de delatar la disposición cronológica original, previa a cualquier reorganización ulterior, incluiría sólo seis de los diez o doce tratados que integraron el total de los Libros de Séneca ${ }^{35}$. Volveremos sobre esta cuestión.

Por su parte, y de manera independiente, pues no parece haber tenido en cuenta el fundamental libro de $\mathrm{K}$. Blüher (cuyo original en alemán es de 1968 , pero la traducción no se publicó hasta 1983), O. T. Impey ${ }^{36}$ establece tres familias: 1) una de escasa calidad textual, constituida según el número y orden de los tratados que contienen el incunable y los códices de la Nacional de Madrid 817 y 8241 , así como los escurialenses T-III-5 y L-II-15; 2) otra, cuyo elemento en común sería la referencia común al traductor como "deán de Santiago, don Alfonso, fijo del obispo de Burgos, don Pablo", en la que entrarian Bib. Nacional de Madrid, ms. 5830 y Escorial, ms. T-III-7 y 3) una última familia de mejor calidad textual, formada por N-II-6 y T-III-4. En este análisis salta a la vista la falta de uniformidad en los criterios aplicados (según el contenido, una calidad textual de la que no se nos da detalles y las rúbricas, para las que cf. supra n. 9) para agrupar los testimonios, así como la arbitrariedad y escasez en la selección de los

\footnotetext{
35 Depende de cómo consideremos dos de los títulos: si pensamos los Dichos de cavalleria como pertenecientes a la serie de traducciones de Cartagena o como una adición espúrea. Para lo primero, véanse los razonamientos de sus editores (T. González Rolán y P. Saquero "El Epitoma rei militaris de Flavio Vegecio traducido al castellano del siglo xv: edición de los Dichos de Séneca en el fecho de la caballevia", Miscelánea Medieval Murciana, 14, 1987-1988, págs. 3-150, especialmente, págs. 127-149), para lo segundo conviene leer las dudas sobre la autoria expresadas por K. Blüher (ob. cit., pág. 141) y por J. Lawrance ("On Fiftheenth-Century Vernacular Humanism", Medieval and Renaissance studies in honour of Robert Brian Ta$t e$, ed. de I. Michael y R. A. Cardwell, Oxford, The Dolphin Book, 1986, págs. 63-79, en especial pág. 69 n. 14). Justamente la ausencia de esta obra en los volúmenes de los testimonios que, como veremos, hay que situar en las ramas altas de la tradición textual, son un argumento más que hay que sumar a los esgrimidos por el estudioso británico.

El segundo título que hay que poner en cuestión, por motivos diferentes, es el llamado en algunos códices Título de la amistanza (o del amigo). Su ausencia de la mayor parte de los códices, su procedencia (de la Tabulatio et expositio Senecae de Lucca Manelli) y el encabezamiento que lleva (título en lugar del acostumbrado libro o tratado) sugieren que se trata de una parte de la Copilaçión (que traduce en su práctica totalidad la citada Tabulatio de Manelli), desgajada en el mismo proceso que describimos antes; v. supra.

${ }^{36}$ O. T. Impey, ob. cit., pág. 475 , n. 6 .
} 
testimonios, todo lo cual distorsiona gravemente el resultado obtenido. Así, por ejemplo, habria que averiguar la calidad textual de los testimonios que pertenecen a la familia segunda o por qué se agrupan los códices escurialenses T-III-4 y N-II-6, pues el número y disposición de los tratados que incluyen no coinciden, lo que hace sospechar en principio que no proceden de un mismo arquetipo ${ }^{37}$. $\mathrm{Y}$ ello, sin entrar en cuestiones puramente textuales, pues hemos podido comprobar al examinar el manuscrito que el códice de El Escorial N-II-6 refleja en los últimos cuadernos un grave problema de copia (a partir del fol. 101r se repite tres veces un mismo cuaderno, uno de los cuales parece el antígrafo de los otros dos). En definitiva, el contenido parece el único criterio externo fiable que puede emplearse para desbrozar la maraña que constituye la transmisión textual de los $\mathrm{Li}$ bros de Séneca.

Un mero examen del contenido de los cuarenta testimonios conocidos hasta ahora muestra que es posible establecer una primera división en tres familias, según el número y orden de tratados que se incluyen. Para ello utilizaremos la metodologia propuesta por G. Orduna ${ }^{38}$ de atender a la constitución de las obras que integran los testimonios, que abordaremos como unidades de transmisión textual, a la manera de los cancioneros, si bien teniendo presentes todas las diferencias que hay entre una colección en prosa y las recopilaciones poéticas ${ }^{39}$. En primer lugar, hay que señalar la exis-

${ }^{37}$ El ms. N-II-6 incluye De la providencia (I,II), De la clemencia, Vida Bienaventurada, Las siete artes liberales, Amonestaciones e dotrinas, De los remedios, Copilación de los dichos de Séneca y las Declamaciones, que es exactamente el orden y tratados que sigue el ms. 201 de la Biblioteca Universitaria de Salamanca y el ms. 6765 de la Biblioteca Nacional de Madrid, asi como (con la omisión de los dos últimos títulos) del códice 9180 de la citada biblioteca y el 22/8/2/ de la Biblioteca March en la misma ciudad. En cambio, T-III-4 consta de Vida bienaventurada, De la providencia (I,II), De la Clemencia, Remedios contra la fortuna, Amonestaciones y doctrinas, Declamaciones y la Copilación, sin que haya otro testimonio que comparta esta disposición, que más bien le une a BNM 17803 y al ms. 1813 de la Biblioteca Universitaria de Salamanca, que contienen las tres primeras obras en el mismo orden, en desorden los réstantes (cf. el Apéndice, al fínal).

${ }^{38}$ Véanse sus trabajos "La collatio externa de los códices como procedimiento para fijar el stemma codicum. Crónicas del Canciller de Ayala", Incipit, 2, 1982, págs. 3-53; "La collatio externa de los códices como procedimiento auxitiar para completar la recensio (las adjciones a la Crónica de Alfonso XI y los capítulos insciales de la Crónica de Pedro I)", Incipit, 4, 1984, págs. 17-34; y "Ecdótica hispánica y el valor estemático de la historia del texto", Romance Philology, 45, 1991, págs. 89-101.

${ }^{39}$ Sobre el método stemmatico externo, véanse los artículos citados de G. Orduna; para el estudio de los cancioneros como volúmenes, algunas de cuyas conclusiones - no todas- habria que aplicar a determinadas antologías en prosa, véase V. Beltrán ("Tipología y génesis de los cancioneros. Los cancioneros de autor", Revista de Filología Española, 78, 1998, págs. 49101), con abundante bibliografia sobre otros trabajos previos del autor y para otras literaturas romances. Aptiqué con éxito tal método para las versiones de Cicerón realizadas por Cartagena, pues, de nuevo se transmitieron juntas De los ofiçios y De senetute bajo el título de los Libros de Tulio (M. Morrás, ed. cit. de Alfonso de Cartagena, especialmente el cap. IV). 
tencia de un pequeño número de manuscritos que incluyen algún título aislado. Son los manuscritos BNM 10199 y Biblioteca de Palacio II-561, que copian la Vida bienaventurada (este último en compañía de las Vidas y costumbres de los filósofos de Walter Burley); BNM 9990, que constituye un ejemplar exento de uno de los dos libros De la clemencia, también incluidos en BNM 5568, junto con los dos libros de De la providencia; y los códices de la Bib. Colombina (Sevilla) ms. 83-6-10, que contiene el Tratado de las adversidades de la fortuna, y HA-COLOM, que a tenor de las escasas noticias que tenemos, recoge tan sólo el Tratado de las cuatro virtudes. De momento los dejaremos de lado en nuestro análisis, pues se trata de testimonios excepcionales en la historia de la transmisión de las versiones de Séneca realizadas por Cartagena, ya que la abrumadura mayoría de los manuscritos son volúmenes en los que se recogen varios de los llamados libros o tratados de Séneca ${ }^{40}$.

La presencia u omisión de lo que -siguiendo los códices- llamaremos libro segundo del De la Providencia (cf. supra n. 34), parece ser entonces la piedra de toque que marca el inicio de la organización de los Tratados de Séneca como un volumen concebido unitariamente, lo que permite distinguir tres grandes ramas. De una parte encontramos una familia que denominaremos $\mathbf{C}^{41}$. Este grupo de códices se caracteriza porque incluye el libro segundo del De la providencia y por la voluntad que se transparenta en él de presentar un volumen organizado de las obras de Séneca en castellano que debía abrirse, en cualquier caso por la Vida bienaventurada. Representa el volumen más completo y representa la forma, al parecer definitiva, de los Libros de Séneca.

Relacionada con esta familia, pues también se incluye $D e$ la providencia $I I$, hay un grupo de testimonios cuya diferencia fundamental es que la Vida bienaventurada y De clemencia aparecen en orden inverso al establecido en $\mathbf{A}$, esto es, siguiendo el orden cronológico en que estas obras fueron vertidas al castellano. Además, en todos los casos faltan los Dichos de cavalleria, incluidos en la mayor parte de los testimonios de $\mathbf{C}$, aunque no en todos ( $c f$. antes, n. 35). Lo interesante de esta familia, que podemos llamar B, es que parece representar un estado intermedio de reorganización de

\footnotetext{
40 Su excepcionalidad los hace sospechosos de ser, en realidad, obras desgajadas de algún arquetipo, incluso de algún original, desencuadernado con el fin de reorganizar su contenido. Aún no hemos tenido ocasión de verificar esta hipótesis, aunque existen evidencias muy notables en este sentido, como se comprobará más adelante.

41 Advertimos que las denominamos familias, pero no se trata de descendientes de subarquetipos. Como se verá, proceden de lo que, en realidad, constituyen originales diferentes si es que se considera el volumen como unidad por si misma, como aquí hacemos. Todavia no hernos establecido con precisión las relaciones entre ellas, por lo que no propondremos un stemma. $C f$, de nuevo, el Apéndice final.
} 
la colección en su forma final ${ }^{42}$. Lo sugiere el número de tratados incluidos, unos ocho, puesto que solo faltan el Pseudo-Séneca Tratado de las cuatro virtudes y los mencionados Dichos de la cavallería, y la disposición del último grupo de títulos, cuyo orden se mantiene en la familia $\mathbf{C}$ y que es el siguiente: Siete artes liberales, Amonestamientos y doctrinas, Los remedios de la fortuna, Copilación y las Declamaciones.

Por último, tenemos un tercer grupo de códices que, como ya habian determinado Blüher e Impey, forman una familia aparte, de la que deriva el incunable de 1491 y las sucesivas impresiones. Nos detendremos en ella con algo más de detalle, puesto que aquí es donde se incluye nuestro códice. Esta familia A se caracteriza porque no incluye el libro segundo de la Providencia. La mera relación de los títulos que contiene revela que se trata de un grupo de testimonios derivados en última instancia de un mismo arquetipo y que éste fue copiado con gran homogeneidad en una serie cuantitativamente importante de manuscritos (Bib. Nacional de Madrid mss. 817, 8241, 12172, 17798; Esc. T-III-5; Bib. de Palacio II-3072 y, añadimos por nuestra parte, Esc. T-III-7 y el códice compostelano (SF)). Todos ellos incluyen, siguiendo siempre el mismo orden los siguientes tratados: Vida Bienaventurada, Siete artes liberales, Amonestamientos y doctrinas, De la providencia de Dios (I), Copilación y Declamaciones (que falta sólo en Esc. T-III-7 y nuestro manuscrito). Además, todos ellos parecen proceder de un subarquetipo en el que la Copilación (que viene después del Libro primero de la providencia de Dios) se había confundido con el Libro segundo de la providencia divi$n a$, tal y como deja ver la rúbrica ( $v$. supra). En cualquier caso, el error muestra que, como adelantábamos párrafos atrás, el antígrafo de ese subarquetipo incluía el citado libro segundo y que éste venía después de la $\mathrm{Co}$ pilación, reflejando así el orden cronológico de las traducciones.

La primera conclusión que se impone es que esta familia ha de ser tenida en cuenta para la reconstrucción critica de las versiones de Séneca, puesto que se remonta a un subarquetipo anterior a los que hemos descrito hasta ahora, que si bien presentan una colección más completa de títulos, necesariamente han de colocarse en un lugar más bajo en el stemma. Por consiguiente, a la hora de realizar la edición crítica de los títulos señalados, los testimonios derivados de A habrán de ser tenidos en cuenta. En segundo lugar, cabe subrayar que carecemos de testimonios que coincidan con la ordenación cronológica; esto es, no hay ningún manuscrito en el que las obras de Séneca aparezcan dispuestas en el orden cronológico que conocemos ${ }^{43}$. Ello

\footnotetext{
${ }^{42}$ Estaria integrada al menos por los mss. Esc. N-II-6, Bib. Univ. de Salamanca 201, Bib. March 22/8/2 y BNM 9180, 6756 (omite VB), 918 y 2683.

${ }^{43}$ Para éste, véase $\mathrm{K}$. Blüher, ob. cit., págs. 135-141.
} 
podría indicar que Cartagena no se apresuraria a difundir las obras a medida que las iba traduciendo y que éstas no se irian sumando sin más, una detrás de otra, sin más criterio que el orden de llegada. Porque, por otra parte, el subarquetipo de $\mathbf{A}$ es claramente resultado de un proceso de ordenación, en el que se han dejado fuera, como ya hemos señalado varias veces, el libro segundo del De la providencia divina, pero también los dos libros del De la clemencia, que sabemos que fueron traducidos en fecha anterior a la Vida bienaventurada y las Siete artes liberales, que en cambio sí son incluidas en el volumen. No pensemos, sin embargo, que estamos ante un proceso de selección, pues de hecho, esta familia tiene todo el aspecto de haberse formado como resultado de haber desgajado las obras que luego son omitidas en $\mathbf{A}$ de un volumen formado por acumulación. Es decir, el punto de partida sería un volumen en el que los títulos se habrían dispuesto por rigurosa cronología: Copilación, De la providencia I, De la clemencia (II,I), De la providencia II, Siete artes liberales, Amonestamientos y dotrinas ${ }^{44}$ y la Vida bienaventurada. Este volumen, que tendría carácter de borrador, sería utilizado por el traductor o, quizá, por alguien cercano a él que actuaría como compilador, para reorganizar los títulos, de modo que el lector pudiera leer todos ellos como un continuo coherente. Para hacerlo, comenzó por invertir el orden cronológico con el fin de situar la Copilación - esto es, la antología- al final, pero al llegar al titulado como Libro II de la providencia, desgajaría los cuadernos que lo contenían, así como los correspondientes a De la clemencia con el fin de coserlos de nuevo o colocarlos tras el Libro I de la providencia, algo que no se llegaría a hacer porque o bien se perdieron los cuademos desgajados, o bien se dejaron de lado en un descuido. Esto último parece lo más plausible dado que "reaparecen" en cabeza del volumen en la familia $\mathbf{B}$, un grupo de manuscritos que, primordialmente es el resultado de recuperar al comienzo de A los títulos "perdidos" y de añadir al final los nuevos títulos traducidos por Cartagena (Los remedios de la fortuna y las Declamaciones) en el transcurso de tiempo que va desde que se constituye el antígrafo de $\mathbf{A}$ $\mathrm{y}$ el de B. Esta hipótesis se convierte casi en certidumbre con el ms. 5568 de la Biblioteca Nacional de Madrid ante la vista, como veremos inmediatamente a continuación. Pero volvamos a los impresos.

Queda por resolver otro pequeño misterio: ¿por qué los impresores sevillanos echaron mano de un manuscrito doblemente defectuoso, por incompleto y por desordenado, cuando hacia 1490 abundaban en circulación $-\mathrm{y}$

\footnotetext{
44 Lo cierto es que no es posibje fechar la traducción de este título a partir de criterios internos (K. Blïher, ob. cit., págs. 135-141), pero el hecho de que aparezca tras las Siete artes liberales en absolutamente todos los códices (y son las dos únicas obras que son copiadas sin excepción en el mismo orden) permite aventurar que fueron vertidas al castellano de manera consecutiva.
} 
debía ser hecho conocido- los códices completos? Un vistazo a lo sucedido con los Libros de Tulio en casa de los impresores Joannes Pegniczer y Magno Herbst en 1501 puede arrojar alguna luz sobre lo ocurrido una década antes en el taller de sus compatriotas y colegas Meinhard Ungut y Stanislaw Polono. Todo parece indicar ${ }^{45}$ que los primeros tuvieron acceso a un códice defectuoso, al que faltaban las epístolas de Juan Alfonso de Zamora y los primeros cuadernos del texto. Ese códice descendia, en última instancia, de un volumen que procedia del scriptorium de Cartagena, que to había desencuadernado para modificar el prólogo a De los ofiçios. Es posible conjeturar entonces, que alguien en Sevilla contaba en su biblioteca con copias de obras de Cartagena y que las había puesto a disposición de los impresores sevillanos. Desafortunadamente, la pista se pierde aquí, de modo que no hemos podido identificar a esa persona, pero ha de recordarse que en el último cuarto de siglo Sevilla se había convertido en uno de los centros más activos de las letras castellanas; piénsese que Fernando de Pulgar y Alfonso de Palencia residieron allí largas temporadas, y más esporádicamente figuras como Alonso de Ortiz, Juan de Lucena y otros letrados que rodeaban la corte de los Reyes Católicos y que se vieron arrastrados al sur cuando la corte instaló sus reales en los aledaños de Granada. Y aunque no hemos tenido ocasión de comprobarlo, es bastante verosímil que una copia directa de la parte desgajada correspondiente al borrador y procedente del ejemplar de la Capilla de la Visitación, donde había mandado depositar ya obispo Alfonso de Cartagena sus obras, haya de ser identificado con el actual manuscrito 5568 de la Biblioteca Nacional de Madrid. Como se sabe ${ }^{46}$, dicho ejemplar perteneció a Antonio de Maluenda, un linaje estrechamente vinculado por matrimonio con los Santa María y que durante generaciones ocupó cargos menores en la catedral de Burgos ${ }^{47}$. La evidencia de que este códice es la parte desgajada del subarquetipo $\mathbf{A}$ o es copia directa de él es que sólo contiene los títulos que allí faltan (De la clemencia, De la Providencia de Dios) y que sus epigrafes siguen la misma formulación que se encuentra, de manera exclusiva, en el incunable de 1491, en Esc. T-III-7 y en el códice compostelano. En esos epígrafes se van numerando los Libros como si, efectivamente, fueran partes constituyentes de un todo ("Aquí comiença el segundo libro de Séneca, que se llama De las siete artes liberales...", "Aquí comiença el terçero libro de Séneca que se llama De amonestamientos y dotrinas...", "Aquí comiença el quarto libro de Séneca

\footnotetext{
${ }^{45}$ M. Morrás, introd. y ed. de Alfonso de Cartagena, Los libros de Tulio. De los oflçios. De la vejez, Alcalá de Henares, Universidad, 1996, págs. 111-134, en especial 117-118.

${ }^{46}$ M. Morrás, "Repertorio de obras, manuscritos y documentos de Alfonso de Cartagena (ca. 1384-1456)", Boletin de la Asociación Hispánica de Literatura Medieval, 5, 1991, pág. 223.

${ }^{47}$ Cf. F. Cantera Burgos, s.v. y L. Sertano, s.v
} 
[...]que se llama De la providençia de Dios", "Aquí comiença el quinto libro de Séneca en que trata cómo en el sabidor...", algo que hasta donde hemos podido comprobar, sólo ocurre en los citados testimonios. Todo parece entonces indicar que Esc. T-III-7 y el códice custodiado hoy en el convento de San Francisco de Santiago de Compostela están estrechamente relacionados entre sí. Su importancia a la hora de estudiar la transmisión textual de las versiones de Séneca por Alfonso de Cartagena es fundamental, ya que estos constituirian el nexo entre el atquetipo $\mathbf{A}$ y el incunable sevillano, y a su vez, junto con BNM 5568, la prueba evidente del proceso de ordenación de los Tratados de Séneca. Juntos, de una parte el códice que perteneció a Antonio de Maluenda (BNM 5568) y, de otra, los citados escurialense (T-III-7) y compostelano (SF), permiten reconstruir la versión primitiva y primera de los dichos Tratados de Séneca. 


\section{APÉNDICE*}

Lista de MANUSCRITOS Y OBRas DE SÉNECA cITADAS

Obras de Séneca, extractos y atribuidas, traducidas por Alfonso de Cartagena entre 1430 y 1434 , por orden cronológico:

1) Copilación de algunos dichos de Séneca [Tabulatio et expositio Senecae de Lucca Manelli] $=\mathrm{co}$

$1^{\text {bis }) ~ T i t u l o ~ d e ~ l a ~ a m i s t a n z a ~ o ~ e l ~ a m i g o ~[e x t r a c t o ~ d e ~ l a ~ T a b u l a t i o] ~}=$ AMI

2) Libro (I) de la providencia de Dios [De providentia] = PRI

3) Libro de la clemencia (II, I) $[$ De clementia $]=$ CLE

4) Libro (II) de la providencia divina $[$ De constantia sapientis] $=$ PRII

5) Libro de las siete artes liberales [Epistola ad Lucilium, núm. LXXX$\mathrm{VIII}]=7_{\mathrm{ART}}$

6) Amonestamientos y doctrinas [De legalibus institutis] $=$ AMO

7) Libro de la vida bienaventurada [De vita beata más De otio] $=\mathrm{vB}$

Sin orden cronológico establecido, pero posteriores a las que se han mencionado y presumiblemente como siguen:

8?) Libro de las declamaciones [Declamationes de Séneca Aneo (el Viejo) $]=$ DECL

9?) Libro de los remedios contra Fortuna [De remediis fortuitorum] $=$ REM

10?) Libro de las cuatro virtudes [Formulae vitae honestae de S. Martín de Braga] $=4 \mathrm{VIR}$

11?) (¿?) Dichos de Séneca en el fecho de cavalleria de Roma [Epitoma rei militaris de Flavio Vegecio] $=\mathrm{CAV}$

\section{ABREVIATURAS DE BIBLIOTECAS}

BNM = Biblioteca Nacional de Madrid

BUS = Biblioteca Universitaria de Salamanca

BMP = Biblioteca Menéndez y Pelayo (Santander)

pal. = Biblioteca Real de Palacio (Madrid)

\footnotetext{
* Se corrigen aquí algunas omisiones y errores de M. Morrás ("Repertorio de obras, manuscritos y documentos de Alfonso de Cartagena (ca. 1384-1456)", Boletin Bibliográfico de la Asociación Hispánica de Litenatura Medieval, 5, 1991, págs. 221-222). Así mismo se matizan, modificándolos en algún caso, algunos de los datos que proporciona $\mathbf{K}$. Blüher (ob. cit., págs. 135-141).
} 


$$
\begin{aligned}
& \text { BM = Biblioteca Bartolomé March (Madrid) } \\
& \mathrm{COL}=\text { Biblioteca Colombina (Sevilla) } \\
& \text { AJ = Biblioteca del Palacio de Ajuda (Lisboa) } \\
& \mathrm{v}=\text { Biblioteca de Valladolid }
\end{aligned}
$$

Familias textuales (filiación no exhaustiva):

\begin{tabular}{lllllll} 
& & \multicolumn{5}{c}{ A } \\
BNM 8241 & VB & 7ART & AMO & PRI & COP & DECL \\
BNM 817 & VB & 7ART & AMO & PRI & COP & DECL \\
BNM 12172 & VB & 7ART & AMO & PRI & COP & DECL \\
BNM 17798 & VB & 7ART & AMO & PRI & COP & DECL \\
Sevilla, 1491 & VB & 7ART & AMO & PRI & COP & DECL \\
Pal. II-3072 & VB & 7ART & AMO & PRI & COP & DECL \\
ET-II-7 & VB & 7ART & AMO & PRI & COP & - \\
SF & VB & 7ART & AMO & PRI & COP & -
\end{tabular}

Relacionados con esta familia:

$\begin{array}{lllllll}\text { ET-III-5 } & \text { VB } & \text { PRI } & \text { COP } & \text { 7ART } & \text { AMO } & \text { DECL } \\ \text { BN 1615 } & \text { VB } & \text { PRI } & \text { 7ART } & \text { AMO } & \text { COP } & - \\ \text { AJ } & \text { PRI } & \text { 7ART } & \text { VB } & \text { AMO } & \text { COP } & \text { DECL }\end{array}$

$\begin{array}{lllllllll}\text { BNM 5568 } & \text { CLEM } & \text { PRI,II } & & & & & & \\ \text { EN-II-6 } & \text { PRI,II } & \text { CLEM } & \text { VB } & \text { 7ART } & \text { AMO } & \text { REM } & \text { COP } & \text { DECL } \\ \text { BUS 201 } & \text { PRI,Il } & \text { CLEM } & \text { VB } & \text { 7ART } & \text { AMO } & \text { REM } & \text { COP } & \text { DECL } \\ \text { BN 6756 } & \text { PRI,II } & \text { CLEM } & \text { VB } & \text { 7ART } & \text { AMO } & \text { REM } & \text { COP } & \text { DECL } \\ \text { M 22/8/2 } & \text { PRI,II } & \text { CLEM } & \text { VB } & \text { 7ART } & \text { AMO } & \text { REM } & - & - \\ \text { BNM 9180 } & \text { PRI,II } & \text { CLEM } & \text { VB } & \text { 7ART } & \text { AMO } & \text { REM } & - & -\end{array}$

Relacionados con esta familia:

$\begin{array}{lllllllll}\text { BUS } 918 & \text { PRI,II } & \text { VB } & \text { CLEM } & \text { 7ART } & & & & \\ \text { BUS } 2683 & \text { PRI,II } & \text { VB } & \text { CLEM } & \text { 7ART } & & & & \\ & & & & & & & & \\ \text { BNM } 6962 & \text { PRI,II } & \text { CLEM } & \text { DECL } & \text { COP } & \text { AMI } & \text { AMO } & \text { 7ART } & \text { 4VIR } \\ \text { BNM 10139 } & \text { PRI,II } & \text { CLEM } & \text { DECL } & \text { COP } & - & \text { AMO } & \text { 7ART } & \\ \text { Pal. II-1878 } & \text { PRI,II } & \text { CLEM } & \text { DECL } & \text { COP } & - & \text { AMO } & \text { 7ART } \\ \text { BUS } 1225 & \text { PRI,II } & \text { CLEM } & \text { DECL } & \text { COP } & - & \text { AMO } & \text { VB- }\end{array}$


PR

ET-III-6

BUS 2197 $\begin{array}{lllllll}\text { PRI,Il } & \text { CLEM AMI } & \text { AMO } & \text { 7ART } & \text { COP } & \text { DECL- } \\ \text { PRI,Il } & \text { CLEM AMl } & \text { AMO } & \text { DECL } & \text { 7ART } & \text { COP } \\ \text { PRI,Il } & \text { CLEM AMI } & \text { DECL } & \text { COP } & \text { AMO } & \text { VB- }\end{array}$

C

BNM 8188 VB PRI,II CLEM 7ART AMO REM COP DECL 4VIR CAV+ BNM 8830 VB PRI,II CLEM 7ART AMO REM COP DECL 4VIR CAV+ ET-III-7 VB PRI,II CLEM 7ART AMO REM COP DECL 4VIR CAV VA 338 VB PRI,II CLEM 7ART AMO REM COP DECL 4VIR CAV Pal. II-1842 VB PRI,II CLEM 7ART AMO REM COP DECL 4VIR CAV BN 10155 VB PRI,II CLEM 7ART AMO REM COP DECL 4VIR MP 38 VB PRI,II CLEM 7ART AMO REM 4VIR COP DECL CAV EL-II-15 VB PRI,II CLEM 7ART AMO REM 4VIR COP - -

Relacionados con esta familia:

$\begin{array}{lllllllllll}\text { BNM 17803 } & \text { VB } & \text { PRI,II } & \text { CLEM } & \text { 7ART } & \text { AMO } & \text { AMI } & - & - & - & \text { CAV } \\ \text { T-III-4 } & \text { VB } & \text { PRI,II } & \text { CLEM } & - & \text { REM } & \text { AMO } & \text { CAV } & \text { DECL } & - & \text { COP+ } \\ \text { BUS 1813 } & \text { VB } & \text { PRI,II } & \text { CLEM } & \text { DECL } & \text { COP } & \text { AMO } & \text { 7ART } & \text { 4VIR } & \text { AMI } & \text { CAV } \\ \text { BUS 318 } & \text { VB } & \text { PRI,II } & - & \text { DECL } & \text { COP } & - & \text { AMO } & \text { 7ART } & \text { 4VIR } & \text { CAV }\end{array}$

